\title{
The Subjective Comfort Test of Autism Hug Machine Portable Seat
}

\author{
Mohamad Izzur Maula ${ }^{1}$, Akhmad Lutfiyan Aji ${ }^{1}$, M. Bahtiar Aliyafi ${ }^{1}$, Ilham Yustar Afif ${ }^{1}$, \\ Muhammad Imam Ammarullah ${ }^{1}$, Tri Indah Winarni ${ }^{2,3,{ }^{*}}$ and J. Jamari ${ }^{1}$
}

\author{
${ }^{1}$ Department of Mechanical Engineering, Faculty of Engineering Diponegoro University, Jl. Prof. Soedarto \\ SH, Tembalang, Semarang (50275), Central Java, Indonesia \\ ${ }^{2}$ Department of Anatomy, Faculty of Medicine Diponegoro University, Jl. Prof. Soedarto SH, Tembalang, \\ Semarang (50275), Central Java, Indonesia \\ ${ }^{3}$ Center for Biomedical Research (CEBIOR), Faculty of Medicine Diponegoro University, Jl. Prof. Soedarto \\ SH, Tembalang, Semarang (50275), Central Java, Indonesia
}

\begin{abstract}
This preliminary study proposes to investigate (i) the mean comfortable deep pressure of Autism Hug Machine Portable Seat (AHMPS) manual pull and inflatable wrap models; and (ii) the effect of using AHMPS in reducing anxiety in children with autism spectrum disorder (ASD). The first phase was done to determine the comfort test. Fifteen healthy adolescents (13 men and 2 women; aged 19-25 years) individuals volunteered to participate in the comfort test in determining the pressure of AHMPS, both manual pull, and inflatable wrap. The second phase was completed in children with ASD, in which the comforting pressure from the first phase was then applied to five children with ASD (4 boys and 1 girl; aged 8-15 years) from the Putra Mandiri Public Special School Semarang. All children were administered both the AHMPS inflatable wrap and manual pull as a deep pressure apparatus while traveling by bus. A pulse oximeter was used to measure heart rate variability (physiological arousal). The mean comfort pressure was obtained from 15 healthy subjects, which was 0.81 psi on the chest and 0.80 psi on the thigh for the manual pull; and 0.65 psi on the chest and $0.45 \mathrm{psi}$ on the thigh for the inflatable wrap. In the second phase, the AHMPS manual pull did not significantly decrease heart rate with $p=0.114$, but the AHMPS inflatable wrap significantly decreased heart rate with a significance value of $p=0.037$. We conclude, therefore, the AHMPS inflatable wrap decreases physiological arousal in children with ASD.
\end{abstract}

Keywords: Autism spectrum disorders, anxiety, comfort test, deep pressure, heart rate.

\section{INTRODUCTION}

Autism is a spectrum developmental disposition caused by complex brain differences that results in behavioral, emotional, communication, and social interaction challenges. Based on the Diagnostic and Statistical Manual of Mental Disorders (DSM-5), autism spectrum disorder (ASD) is a part of the Neurodevelopmental Disorders group, with attention deficit hyperactivity disorder (ADHD) [1]. ASD is characterized by persistent deficits in reciprocating social interaction, communication, and repetitive behavior. The disorder occurs during a developmental period, usually in childhood, but may appear late when social demands exceed acceptable capacity [2]. The prevalence of ASD has recently increased worldwide. However, the estimated prevalence of ASD in Asia is lower than in Western countries. The overall prevalence of ASD is $0.36 \%(95 \% \mathrm{Cl}: 0.16-0.79 \%)$ in Asia, and $2.79 \%$ in the USA [3]. However, the number and increase of people with ASD in Indonesia are probably inaccurate. The estimated number of autistic children in Indonesia in early 2020 is around 3 million people. The amount is based on estimated data from

*Address correspondence to this author at the Center for Biomedical Research, Faculty of Medicine Diponegoro University, JI. Prof. Soedarto SH, Tembalang, Semarang (50275), Central Java, Indonesia; Tel: +62248412311; Fax: +62248454714; E-mail: triindahw@gmail.com, tri.winarni@lecturer.undip.ac.id the Ministry of Women's Empowerment and Child Protection of the Republic of Indonesia in 2018; there were around 2.4 million ASD people in Indonesia, with an increase in new people reaching 500 people per year [4].

Many treatments for people with autism have been developed and applied as a means of therapy and treatment for each of their symptoms, such as behavioral treatment, psychopharmacological treatment, speech and language treatment, occupational treatment, social skills training, and complementary treatment [5]. The therapy that is reported to have a good effect is behavioral treatment $[5,6]$. However, accessibility and affordability are very low among the population in low-middle income countries [6,7]. A favorable treatment that shows immediate results is sensory integration therapy (SIT), which is included in complementary treatment $[5,6]$. Deep pressure treatment (DPT) is one type of SIT, which suggests certain pressure for a certain period to provide a calming effect and reduce unwanted behaviors caused by anxiety $[8,9]$. As a therapeutic method widely used in occupational therapy, deep pressure is reported to produce a calming effect by modulating the autonomic nervous system $[10,11]$.

The deep pressure technique has been used in the past by Krauss [12]. It is a device called Hug'm 
Apparatus. Two stacked air mattresses surrounded by a canvas and pulley system applied to the person offered deep pressure on the body. This was applied to 23 healthy individuals to evaluate Hug'm apparatus using the state-trait anxiety inventory (STAI) questionnaire as a subjective measurement and heart rate variability measurement for an objective evaluation. Krauss reported that Hug'm deep pressure did not significantly reduce state anxiety on objective and subjective measurements. However, it was found the Hug'm had a calming effect, as evidenced by a significant reduction in the state of anxiety in the control group. Thus, a need for further studies is conducted on the calming effects of deep pressure [12].

Grandin [13] introduced a therapeutic tool to relieve stress (stress-relieving device) or usually known as a hug machine. This tool, called the "Squeeze Machine", was developed based on her own experience as an ASD individual. The squeeze machine provides a hug simulation by applying pressure to the child's body to provide a calming effect. The squeeze machine works laterally by $\mathrm{V}$ pad and presses the whole body. Grandin reported that the squeeze machine has a relaxing effect on normal adults. In addition to Grandin, Lorna King also reports the squeeze machine's positive effect on ASD children [8].

Edelson [14] then tested Grandin's squeeze machine's long-term effect on 5 children with anxiety. The test was conducted subjectively using Connor's Parent Rating Scale (CPRS) and objectively using the galvanic skin response (GSR). Hug machines are reported to provide benefits for children who have high anxiety. A further study was conducted by Minoura [15], who also used Grandin's squeeze machine with minor modifications. Minoura added bead-filled cushions in order to allow deep pressure to reach previously unreachable areas then used subjective reports and peri-personal space (PPS) measurements. Another study was conducted by Reynolds [16], who used the Vayu Vest as a deep pressure intervention tool. Participants in this study were asked to use a device and control the pressure by themselves until they felt a hug's sensation. Then the effect was investigated objectively on changes in skin conductance and heart rate. All of the above experiments reported the advantages of deep pressure use in providing comfort but did not determine the amount of pressure needed. The subjects themselves determined the amount of pressure they wanted. They also did not report whether the selected pressure ranges were relatively close or far away, so it is not known what standard of pressure is comfortable to use as a deep pressure stimulant.

More than $90 \%$ of children with ASD have sensory processing disorders [17]. Therefore, they often experience distraction when receiving sensory input, such as unusual/excessive sound, touch, movement, and vision. Yonkman [18] reported that children with ASD would become aggressive and show self-injurious behavior when traveling in a vehicle. Afif [19] then designed the Hug Machine Portable Seat to provide a deep pressure effect and be used in public vehicles. However, this tool has not been tested experimentally. This study aims to obtain comforting pressure and investigate the effect of short-term use of autism hug machine portable seat (AHMPS) manual pull and inflatable wrap models on children with ASD in public transportation (bus).

\section{MATERIAL AND METHODS}

\section{Study Design and Participants}

This experimental study was separated into two phases. The first phase was participated in by healthy adolescents to investigate the mean comfortable pressure. The selection of healthy adolescents rather than children with ASD as respondents was because children with ASD cannot provide appropriate feedback (verbal) of comfort when using deep pressure [12]. The second phase was participated by ASD children randomly chosen from Putra Mandiri Public Special School, Central Java, Semarang, Indonesia. The school's condition was registered as a baseline condition for children, then getting on the bus was registered as a stressor. A parallel pretest/posttest design was conducted on the bus to investigate the effect of both manual pull and inflatable wrap deep pressures. This study examined short-term effect so that we only did once for each participant $[15,16,20]$.

\section{Ethics}

Approval of this study was carried out by the Health Research Ethics Committee Faculty of Medicine Diponegoro University No. 08/EC/FKUNDIP/I/2019. The consent was obtained from all participants in the first phase, and parent consent was collected for the two phases.

\section{Instruments}

\section{Hug Machine}

AHMPS manual pull and inflatable wrap models invented in the previous study were used [19]. The 


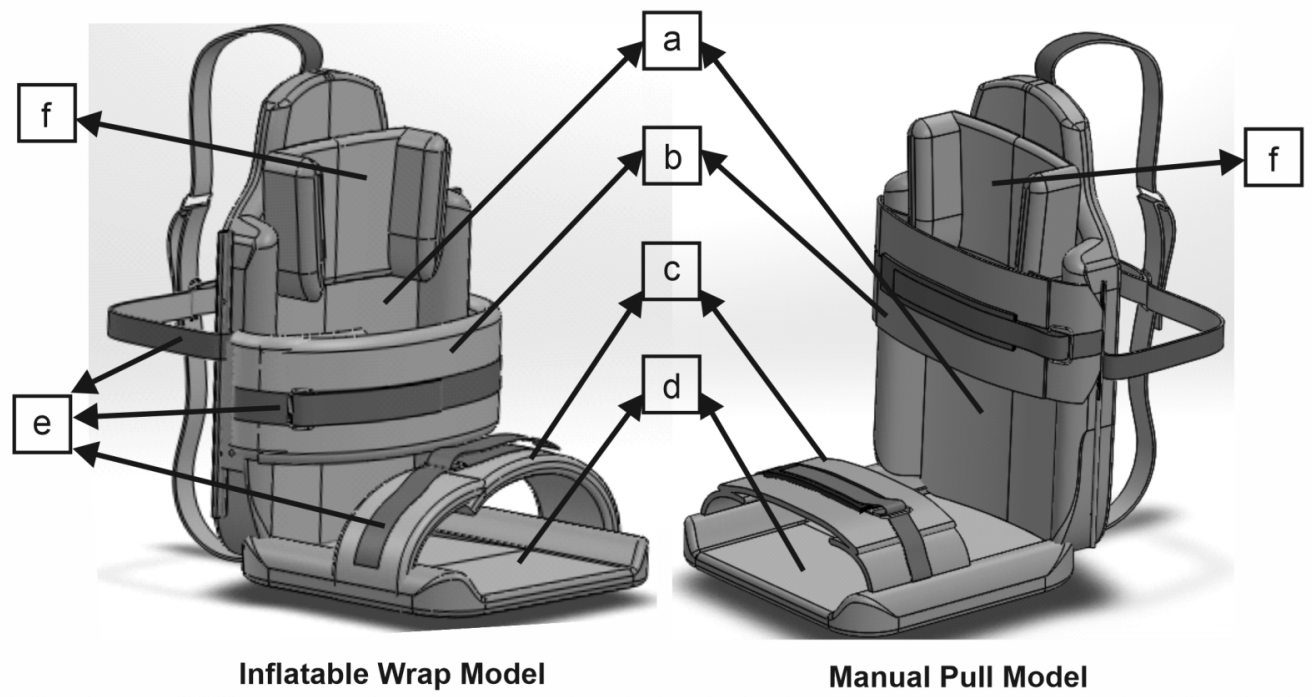

\begin{tabular}{|c|c|c|c|}
\hline \multirow{2}{*}{ Parts } & \multirow{2}{*}{ Name } & \multicolumn{2}{|c|}{ Bill of materials } \\
\cline { 3 - 4 } & & Inflatable wrap & Manual pull \\
\hline \hline a & Backrest & Foam; semi-leather fabric & Foam; semi-leather fabric \\
\hline b & Chest hugger & Balloon; semi-leather fabric & Soft foam; semi-leather fabric \\
\hline c & Thigh hugger & Balloon; semi-leather fabric & Soft foam; semi-leather fabric \\
\hline d & Sitting part & Foam; semi-leather fabric & Foam; semi-leather fabric \\
\hline e & Chair straps & Velcro & Velcro \\
\hline f & Headrest & Foam; semi-leather fabric & Foam; semi-leather fabric \\
\hline
\end{tabular}

Figure 1: AHMPS Inflatable Wrap Model (left); and Manual Pull Model (right).

AHMPS manual pull is a portable seat with foam straps in the chest and thigh that can press the user's body when straps are pulled like a safety belt. Load sensors were used to measure the pressure on AHMPS manual pull, and then the results were changed to a unit of pressure needed and divided by the hug area. Also, differential pressure sensors have been used to measure the pressure on AHMPS inflatable wrap. The AHMPS inflatable wrap had the same shape as the manual pull model, but it had a different type of hug strap. These straps contained a balloon inflated by a pump that was pressed on the user's body (See Figure 1).

\section{Heart Rate}

Parasympathetic activities were investigated through the heart rate variability [21]. Heart rate is useful to measure safety and physiological anxiety [2224]. Pulse oximeter Elitech ${ }^{\circledR}$ FOX-1 (Surabaya, Indonesia) was used to measure heart rate. The Pulse oximeter as Photoplethysmography (PPG) device is a simple and non-invasive optical method for investigating individual's physiological parameters like oxygen saturation, heart rate, respiratory rate, and blood pressure. Infrared light from the device reads changes in blood concentration which is interpreted as a pulse rate in beat per minute (BPM) [25].

\section{Procedure}

In the first phase, healthy adolescents were asked to apply AHMPS and adjusted the load of pressure, then give a verbal judgment when participant feel comfortable without knowing the amount of pressure. The researcher would note the amount of pressure as a comfortable pressure level. The pressure was loaded with no prior pressure determination. The pressure continued to increase or decrease until the subject said, "it is comfortable", then the researcher noted the pressure. The mean pressure from the first phase was then used in the second phase.

In the second phase of the experiment, the heart rate of five children with ASD was measured at school and registered as a baseline condition before getting on the bus. The subject sat on the chair without AHMPS, and then pulse was placed on the left index finger. Pulse oximeter displays the heart rate in beat per minute (BPM) after approximately 10 seconds, and the researcher noted it. 
After that, the child with ASD entered the bus, which was on standby with the engine running. Heart rate was measured and registered as a pretest. Chest and thigh hugger then was putted on. In the manual pull model, the hugger was pulled manually by the researcher to tighten and give the "comfort" pressure. In the inflatable wrap model, a hug was inflated with a pump by the researcher as much as "comfort" pressure was achieved. Deep pressure was applied for 15 minutes for each child, then released. The heart rate was measured as a posttest.

\section{Statistical Analysis}

Comparative analysis was used to investigate the effectiveness of the AHMPS between pretest and posttest with $95 \% \mathrm{Cl}$. Kolmogorov-Smirnov as a normality test was used because of the limited of subject number $(n=5)$ [26]. Paired sample T-test was applied for the heart rate comparative analysis [27].

\section{RESULTS}

The first phase was followed by 15 healthy adolescents aged $19-25$ years (13 male, 2 female). The second phase was followed by 5 children with ASD aged 8-15 years (4 boys, 1 girl).

The most comfortable hug machine pressure was taken from the average pressure selected $(n=15), 0.81$ psi for the chest, and 0.80 psi for the manual pull's thigh pressure, while $0.65 \mathrm{psi}$ for the chest and $0.45 \mathrm{psi}$ for the high pressure of the inflatable wrap (See Table 1).

In the second phase, heart rate was measured three times, i.e., baseline condition, pretest, and posttest. Before using the AHMPS, heart rate from 4 (90\%) children with ASD were increased between regular condition and pretest. This indicates that getting into the bus makes children with ASDs more anxious. After applying the comfortable pressure using AHMPS,

Table 1: Mean Value of Comfort Pressure Test Result from Phase 1 in Manual Pull and Inflatable Wrap Model

\begin{tabular}{|c|c|c|c|c|c|c|}
\hline \multirow{2}{*}{ Hug machine models } & \multirow{2}{*}{$\begin{array}{c}\text { Strap } \\
\text { Location }\end{array}$} & \multirow{2}{*}{$\mathbf{N}$} & \multicolumn{4}{|c|}{ Pressure (psi) } \\
\hline & & & Min. & Max. & Mean & SD \\
\hline \multirow{2}{*}{ Manual Pull } & Chest & 15 & 0.78 & 0.89 & 0.81 & 0.03114 \\
\hline & Thigh & 15 & 0.65 & 0.88 & 0.80 & 0.05738 \\
\hline \multirow{2}{*}{ Inflatable Wrap } & Chest & 15 & 0.53 & 0.72 & 0.65 & 0.06247 \\
\hline & Thigh & 15 & 0.40 & 0.55 & 0.45 & 0.04263 \\
\hline
\end{tabular}

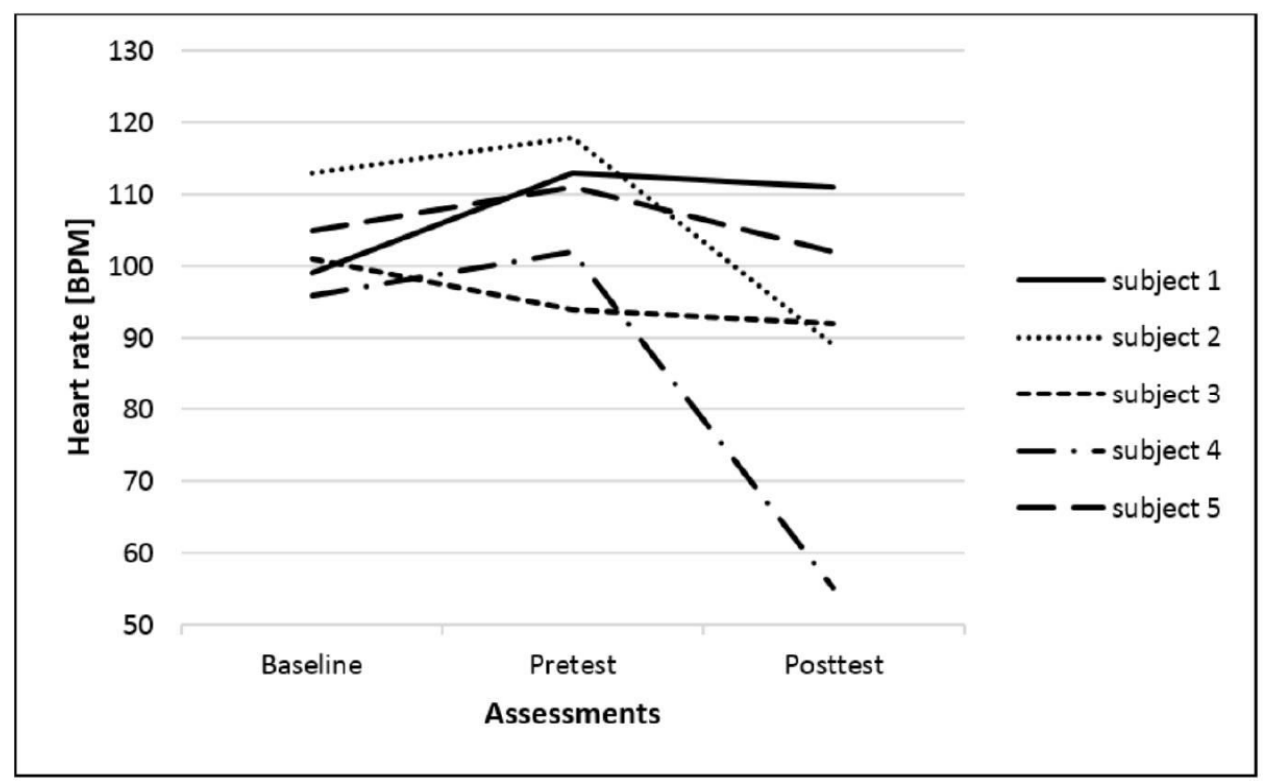

Figure 2: Baseline, Pretest, and Posttest Heart Rate Variability in Children with Manual Pull Model. 


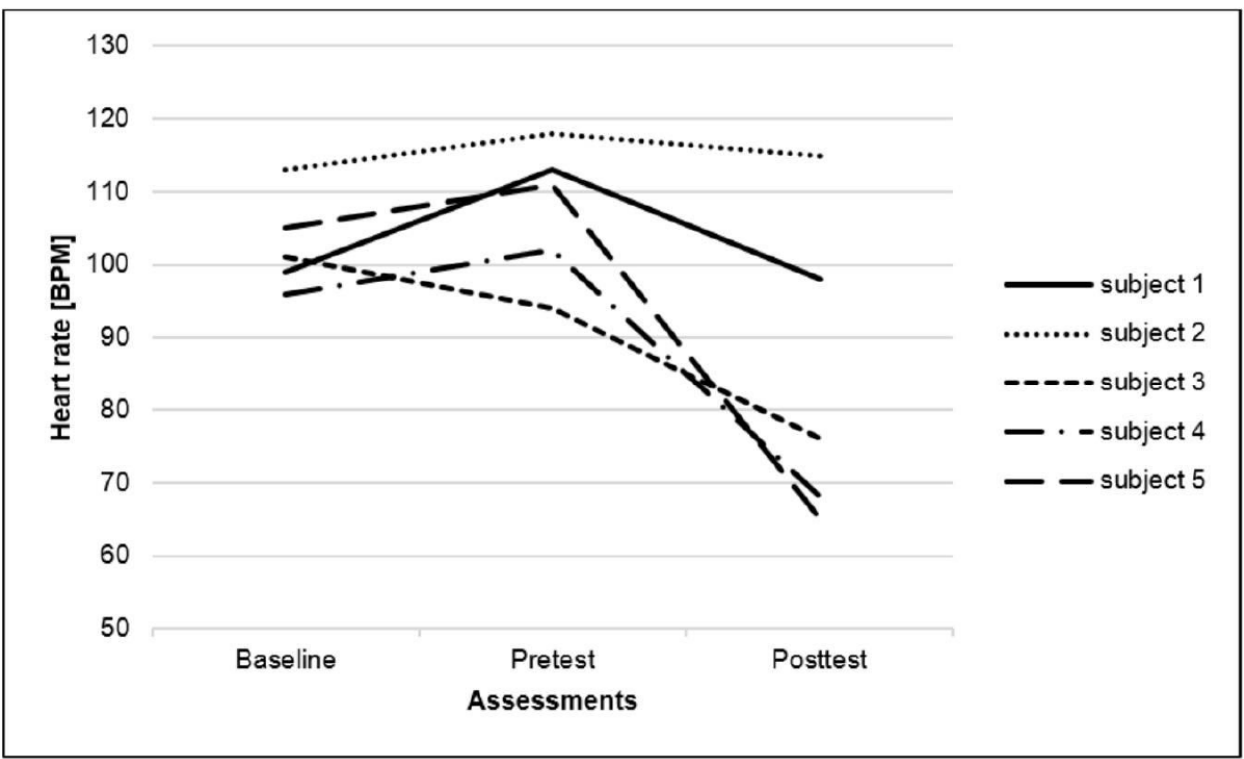

Figure 3: Baseline, Pretest, and Posttest Heart Rate Variability in Children with Inflatable Wrap Model.

Table 2: Paired Pretest Posttest in AHMPS Manual Pull and Inflatable Wrap Models

\begin{tabular}{|c|c|c|c|c|}
\hline AHMPS models & Assessments & Mean & N & SD \\
\hline \hline \multirow{2}{*}{ AHMPS Manual Pull } & Pretest & 107.60 & 5 & 9.555 \\
\cline { 2 - 5 } & Posttest & 89.80 & 5 & 21.300 \\
\hline \multirow{2}{*}{ AHMPS Inflatable Wrap } & Pretest & 107.60 & 5 & 9.555 \\
\cline { 2 - 5 } & Posttest & 84.40 & 5 & 21.431 \\
\hline
\end{tabular}

${ }^{*}=p<0.05$ (significant)

the charts show the decreasing heart rate of pretestposttest using manual pull and inflatable wrap models (See Figures 2 \& 3).

The effect of AHMPS on heart rate (pretest and posttest) was described (See Table 2). The mean heart rate in both manual pull and inflatable wrap models decreased between pretest and posttest. The manual pull model did not significantly decrease the heart rate $(p=0.114)$, whereas the inflatable wrap significantly decreased the heart rate $(p=0.037)$.

\section{DISCUSSIONS}

In the first phase of the experiment, the comfortable pressure obtained from 15 healthy adolescents had differences between the manual pull model and the inflatable wrap model. The comforting pressure at manual pull was greater compared to the inflatable wrap model. It could be due to the differences in the pressure generation mechanism. The inflatable wrap provides axial compression, allowing a broader contact area to be formed than manual pull models (See Figure 4).
A larger contact area on the same body part will provide a better deep pressure advantage [15]. It is in line with the second phase study results, where the AHMPS inflatable wrap model provides more significant results in reducing the anxiety of children with ASD when riding the bus, compared to the insignificant manual pull model.

The autonomic nervous system is an involuntary control of visceromotor function, especially to maintain the cell's physiological integrity, tissue, and organs. Thus, the ANS is critical for the adaptation of anxiety [28]. There are organ responses to ANS activation, including heart rate, sweat glands, digestive glands, bronchial smooth muscles, and eye sphincter muscles [29]. Heart rate variability is commonly used to investigate the regulation and modulation of ANS. Decreasing heart rate in phase two resembles a calming effect of AHMPS, which was the decreasing of anxiety $[8,21-25,30]$. The Inflatable wrap models can reduce anxiety in children with ASD. Apart from the difference in the contact area, the inflatable wrap provides an inward force direction, allowing less friction 


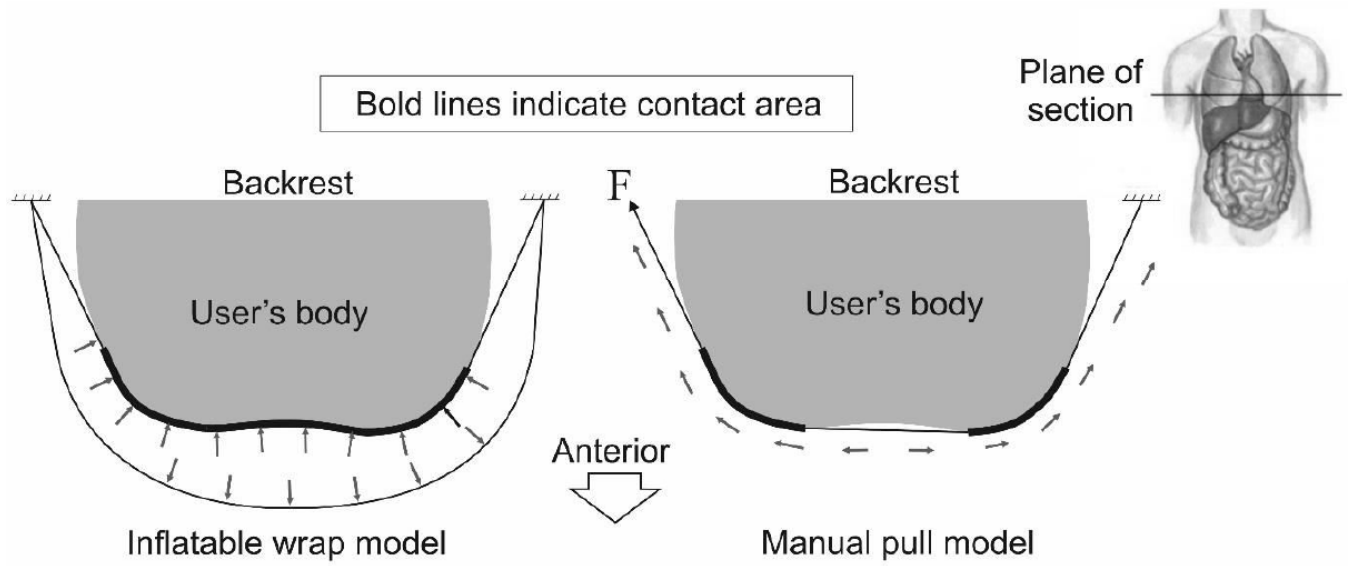

Figure 4: The Difference of Pressure Generation and Contact Area in Inflatable Wrap and Manual Pull Models.

than the manual pull. It will give a more comfortable effect.

\section{STUDY LIMITATION}

This preliminary study was conducted on healthy adolescents to assess comfort pressure (in phase one) followed by children with ASD to validate and ensure the effect of pressure (in phase two). Although the results show a positive effect, it may be more influential for future studies to use verbal adolescents with ASD when assessing comfortable pressure. The bus used in the experiment was only occupied by the participants, teachers, and researchers with no public passengers. Thus, the stressor may not be the same as in the original conditions for being in public transportation.

\section{ACKNOWLEDGEMENT}

This study was granted by Diponegoro University in the scheme of International Research Publication No. 329-83/UN7.P4.3/PP/2019. We are very grateful to all participants who willing to involve in this study, thanks to the teachers of the Putra Mandiri Public Special School, Semarang, for the enormous help in conducting this study.

\section{REFERENCES}

[1] American Psychiatric Association. Diagnostic and statistical manual of mental disorders (DSM-5). 5th Ed. American Psychiatric Pub 2013. https://doi.org/10.1176/appi.books.9780890425596

[2] World Health Organization. International statistical classification of diseases and related health problems (ICD11) [Internet] 2020 [cited 2021 Jan 6]. Available from: https://icd.who.int/

[3] Qu S, Lu Y, Li Y, Shi J, Cui H, Gu Y, et al. prevalence of autism spectrum disorder in Asia: A systematic review and meta-analysis. Psychiatry Res 2020; 284: 112679. https://doi.org/10.1016/j.psychres.2019.112679
[4] Ministry of Women's Empowerment and Child Protection of the Republic of Indonesia. Hari peduli autisme sedunia: kenali gejalanya, pahami keadaannya (World autism care day: recognize the symptoms, understand the conditions) [Internet] 2018 [cited 2020 Oct 27]. Available from: https://www.kemenpppa.go.id/index.php/page/read/31/1682/ hari-peduli-autisme-sedunia-kenali-gejalanya-pahamikeadaannya

[5] McDougle CJ. Autism spectrum disorder. Oxford University Press; 2016. https://doi.org/10.1093/med/9780199349722.001.0001

[6] Matson JL. Handbook of Treatments for Autism Spectrum Disorder. Springer; 2017. https://doi.org/10.1007/978-3-319-61738-1

[7] Samms-Vaughan ME. The status of early identification and early intervention in autism spectrum disorders in lower-and middle-income countries. Int J Speech Lang Pathol 2014 16(1): $30-5$.

https://doi.org/10.3109/17549507.2013.866271

[8] Grandin T. Calming effects of deep touch pressure in patients with autistic disorder, college students, and animals. J Child Adolesc Psychopharmacol 1992; 2(1): 63-72. https://doi.org/10.1089/cap.1992.2.63

[9] Taylor CJ, Spriggs AD, Ault MJ, Flanagan S, Sartini EC. A systematic review of weighted vests with individuals with autism spectrum disorder. Res Autism Spectr Disord 2017; 37: $49-60$. https://doi.org/10.1016/j.rasd.2017.03.003

[10] Ayres AJ. Bausteine der kindlichen Entwicklung: Sensorische Integration verstehen und anwenden-Das Original in moderner Neuauflage (Building blocks of child development: Understanding and applying sensory integration - the original in a modern new edition). Springer-Verlag; 2013.

https://doi.org/10.1007/978-3-642-30177-3

[11] Ayres AJ. Sensory integration and learning disorders. Western Psychological Services; 1972.

[12] Krauss KE. The Effects of Deep Pressure Touch on Anxiety. Am J Occup Ther [Internet]. 1987 Jun 1; 41(6): 366-73. https://doi.org/10.5014/ajot.41.6.366

[13] Grandin T. My experiences as an autistic child and review of selected literature. J Orthomol Psych 1984; 13(3): 144-74.

[14] Edelson SM, Edelson MG, Kerr DCR, Grandin T. Behavioral and physiological effects of deep pressure on children with autism: A pilot study evaluating the efficacy of Grandin's Hug Machine. Am J Occup Ther 1999; 53(2): 145-52. https://doi.org/10.5014/ajot.53.2.145

[15] Minoura M, Tani I, Ishii T, Gunji Y-P. Observing the Transformation of Bodily Self-consciousness in the Squeezemachine Experiment. J Vis Exp 2019; (145): e59263. https://doi.org/10.3791/59263 
[16] Reynolds S, Lane SJ, Mullen B. Effects of deep pressure stimulation on physiological arousal. Am J Occup Ther 2015; 69(3): 6903350010p1-5. https://doi.org/10.5014/ajot.2015.015560

[17] Leekam SR, Nieto C, Libby SJ, Wing L, Gould J. Describing the sensory abnormalities of children and adults with autism. J Autism Dev Disord 2007; 37(5): 894-910. https://doi.org/10.1007/s10803-006-0218-7

[18] Yonkman J, Lawler B, Talty J, O'Neil J, Bull M. Safely transporting children with autism spectrum disorder: Evaluation and intervention. Am J Occup Ther 2013; 67(6): 711-6. https://doi.org/10.5014/ajot.2013.008250

[19] Afif IY, Maula MI, Aliyafi MB, Aji AL, Winarni TI, Jamari J. Design of Hug Machine Portable Seat for Autistic Children in Public Transport Application. In: IOP Conference Series: Materials Science and Engineering. IOP Publishing; 2021. p. 12034.

\section{https://doi.org/10.1088/1757-899X/1096/1/012034}

[20] Foo E, Lee JW, Ozbek S, Holschuh B. Preliminary study of the subjective comfort and emotional effects of on-body compression. In: Proceedings of the 2018 ACM International Symposium on Wearable Computers 2018; pp. 128-31. https://doi.org/10.1145/3267242.3267279

[21] Wang C-A, Baird T, Huang J, Coutinho JD, Brien DC, Munoz DP. Arousal effects on pupil size, heart rate, and skin conductance in an emotional face task. Front Neurol 2018; 9: 1029.

https://doi.org/10.3389/fneur.2018.01029

[22] Becklund AL, Rapp-McCall L, Nudo J. Using weighted blankets in an inpatient mental health hospital to decrease anxiety. J Integr Med 2021; 19(2): 129-34. https://doi.org/10.1016/j.joim.2020.11.004

[23] Champagne T, Mullen B, Dickson D, Krishnamurty S. Evaluating the Safety and Effectiveness of the Weighted Blanket With Adults During an Inpatient Mental Health
Hospitalization. Occup Ther Ment Heal [Internet] 2015; 31(3): 211-33. https://doi.org/10.1080/0164212X.2015.1066220

[24] Mullen B, Champagne T, Krishnamurty S, Dickson D, Gao RX. Exploring the Safety and Therapeutic Effects of Deep Pressure Stimulation Using a Weighted Blanket. Occup Ther Ment Heal [Internet] 2008; 24(1): 65-89. https://doi.org/10.1300/J004v24n01 05

[25] Ashisha GR, Mary XA. Advances in Photoplethysmogram and Electrocardiogram Signal Analysis for Wearable Applications. In: Intelligence in Big Data TechnologiesBeyond the Hype. Springer; 2021; pp. 527-34. https://doi.org/10.1007/978-981-15-5285-4 52

[26] Motulsky $\mathrm{H}$. Intuitive biostatistics: a nonmathematical guide to statistical thinking. 4th ed. Oxford University Press, USA; 2014; p. 230.

[27] Drezner Z, Turel O. Normalizing variables with too-frequent values using a Kolmogorov-Smirnov test: A practical approach. Comput Ind Eng [Internet] 2011; 61(4): 1240-4. https://doi.org/10.1016/j.cie.2011.07.015

[28] Morilak DA, Barrera G, Echevarria DJ, Garcia AS Hernandez A, Ma S, et al. Role of brain norepinephrine in the behavioral response to stress. Prog NeuroPsychopharmacology Biol Psychiatry [Internet] 2005; 29(8): 1214-24. https://doi.org/10.1016/j.pnpbp.2005.08.007

[29] Wehrwein EA, Orer HS, Barman SM. Overview of the anatomy, physiology, and pharmacology of the autonomic nervous system. Compr Physiol 2011; 6(3): 1239-78. https://doi.org/10.1002/cphy.c150037

[30] Awad AA, Ghobashy MAM, Ouda W, Stout RG, Silverman DG, Shelley KH. Different responses of ear and finger pulse oximeter wave form to cold pressor test. Anesth Analg 2001; 92(6): 1483-6. https://doi.org/10.1097/00000539-200106000-00026

Received on 26-03-2021

Published on 30-04-2021

https://doi.org/10.6000/2292-2598.2021.09.02.4

(c) 2021 Maula et al.; Licensee Lifescience Global.

This is an open access article licensed under the terms of the Creative Commons Attribution Non-Commercial License (http://creativecommons.org/licenses/by-nc/3.0/) which permits unrestricted, non-commercial use, distribution and reproduction in any medium, provided the work is properly cited. 